\title{
Are there differences between the expectations of parents, nurses and physicians when using music in NICU?
}

\author{
Pölkki Tarja ${ }^{1}$, Korhonen Anne ${ }^{2}$, Saarela Timo ${ }^{2}$, Peltoniemi Outi ${ }^{2}$, Laukkala Helena ${ }^{3}$ \\ ${ }^{1}$ Department of Nursing Science, Institute of Health Sciences, University of Oulu, Oulu, Finland \\ ${ }^{2}$ Department of Pediatrics and Adolescence, Oulu University Hospital, Oulu, Finland \\ ${ }^{3}$ Department of Research Methodology, University of Lapland, Rovaniemi, Finland \\ Email: tarja.polkki@nic.fi
}

Received 30 June 2012; revised 1 August 2012; accepted 10 August 2012

\begin{abstract}
This paper aimed to describe and explain the expectations concerning the use of music in NICU from the viewpoints of parents, nurses and physicians. The relevant questionnaires were distributed to 836 participants who were recruited from the country's five university hospitals $(n=508$, response rate 61$)$. Slightly over half of the participants preferred recorded music versus live music in the NICU. They strongly expected that their preferred music could be beneficial both for the infants, parents and staff. The parents agreed most that live music is the most suitable choice for infants $(p<0.001)$, and that the music could especially benefit the infant $(p<0.001)$ and parents $(p<$ 0.001) compared with the nurses' and physicians' preferences. Some background details such as age, average length of time listening to music, musical training and experiences of using music provided significant explanations for the participants' expectations. In conclusion, there were significant differences between the groups of the respondents concerning the type of the preferred music and its expected effects. This highlights the importance of discussion with the caregivers when taking music into regular use in the neonatal intensive care units.
\end{abstract}

Keywords: Music; Neonatal Intensive Care; Parents; Health Care Providers; Expectations

\section{INTRODUCTION}

The neonatal intensive care unit (NICU) as an environment is a potential source of stress for infants. Preterm or ill term neonates are exposed to several painful procedures, but also to ambient noise caused by monitor alarms, mechanical noises and voices that often exceed recommendation levels [1-3]. By 26 - 28 weeks gestational age (GA), the auditory system is sufficiently mature for loud noise to induce negative short-term effects in the cardiovascular and respiratory systems of infants [3].

It has been suggested that music is an auditory stimulus that could mask aversive auditory stimuli, and lead to a more harmonious, reassuring environment for the infants in NICU [4-6]. Music includes melody, rhythm, harmony, timbre, form and style, with many cognitive elements that enable the promotion of neurological organization. Sound in the NICU should be soothing, constant, stable and relatively unchanging, and therefore live singing and lullabies are usually most recommendable to infants [6]. However, music with irregular frequencies and inconsistent patterns is assumed to be particularly harmful for developing the auditory system of prematurely born infants [7]. Recommendations specify that continuous sound should not exceed an hourly equivalent sound level of $50 \mathrm{~A}$-weighted decibels (dBA) [7,8], and music not exceeding $75 \mathrm{~dB}$ is preferred in NICU $[9,10]$.

Music can produce many positive effects for infants during their hospitalization. For example, numerous studies have concluded that music can reduce stress and increase physiological stability, including improvement in physiological outcomes such as oxygen saturation, heart rate, respiratory rate and blood pressure, as well as in behavioral state, pain and sleep [5,11-13]. There is also evidence that music has positive consequences on long-term outcomes, including better growth rates and non-nutritive sucking, and reduced length of hospitalization [14-18]. In addition, a few studies have shown that music could also benefit parents and health care providers in the NICU. It has improved parent-infant bonding [19], and reduced maternal anxiety [20,21], but has also had positive effects on the staff's moods, attitudes and interaction with both infants and parents [11,22]. Most of the music interventions used in earlier studies have consisted of recorded music or combination music with other interventions, and only a few studies have examined merely the effects of live music $[4,6]$.

Up to now, we have no studies on how the caregivers 
including parents, nurses and physicians participating in the infants' care think about the preferred music and its use in NICU, and if there is any significant agreement between their viewpoints. Indeed, we know that parents have a crucial role in neonatal care, and we believe they should be encouraged to have greater involvement in their infants' pain care [23]. In addition, it is the health care providers' responsibility to reduce the infants stress, and, consequently, they have a very prominent role in determining what kinds of interventions are chosen in the hospital.

The purpose of our study was to describe and explain the expectations concerning the use of music in NICU from the viewpoints of parents, nurses and physicians. It is known that musical preferences play a significant role when selecting the music intervention in practice [24]. Therefore, the specific research questions were as follows: 1) Do parents, nurses and physicians prefer live or recorded music in the NICU? 2) What are the effects of their preferred music on the infants, parents and staff according to participants' expectations? 3) Which background details explain the expectations of using music in the NICU?

\section{METHODS}

\subsection{Participants and Settings}

The questionnaires were distributed to 836 participants (300 parents, 256 nurses, 280 physicians) who were recruited from the country's five university hospitals (Helsinki, Kuopio, Oulu, Tampere and Turku) located in different geographical areas of Finland. All nurses working in neonatal intensive care units and physicians in pediatric units of the aforementioned hospitals were invited to participate in the study. In addition, parents who were the infant's mother or father, had their baby hospitalized in the NICU and were able to understand the Finnish language were recruited to the study.

The questionnaires were distributed to parents and nurses via the nursing managers and to physicians via the secretaries of the hospitals. Altogether 535 questionnaires were returned, out of which 34 were excluded due to missing data. Finally, 508 questionnaires were accepted, giving an average response rate of 61 (parents $66 \%$, nurses $82 \%$, physicians $36 \%$ ). The completed questionnaires were mailed back to the researcher in prestamped return envelopes.

\subsection{Survey Instrument}

A survey instrument for this study was developed based on the earlier research literature $[6,14,19]$, and the suggestions of an expert panel. In addition, a few questions were added and modified from the study of Kemper et al.
[25], who originally developed their instrument for staff working in a neonatal intensive care unit. The questionnaire reported in this study comprised three sections. Section 1 inquired about the demographic details of the participants (8 items) (see Table 1), and Section 2 included one question about participants' preferred music in the NICU (live or recorded music including alternative types of them) (see Table 2). The questions in the above-mentioned sections were dichotomous or multiple choice questions. Section 3 elicited information about the participants' expectations concerning the effects of their preferred music for infants, parents and staff (21 items) (see Table 3). The replies were given on a five-point Likert-type scale ranging from "totally agree", "agree to some extent", "don't know", "disagree to some extent", and "totally disagree".

The questionnaire was piloted among 69 nurses and 27 parents caring for infants in four pediatric units that were not included in the final study. An expert panel participated in revising the instrument, consisting of three music therapists, one neonatal intensive care nurse, one neonatologist, three researchers specialized in neonatal care, and one statistician. Based on the comments of the panel and the pilot study only a few questions needed to be clarified and added to the instrument, including the types of recorded music, and the expectations concerning the preferred type of music for infants.

Exploratory factor analysis was employed when evaluating the construct validity of the instrument. Only items that correlated with each other (correlations $\geq 0.3$ ) were taken into the factor analysis. As a result, three factor solutions about the expectations regarding the preferred music for infants, parents and staff were generated, which accounted for $56 \%$ of the total variance. The eigenvalues varied between 1.4 and 7.9 , and the factor loadings between 0.48 and 0.86 , while the communalities were between 0.33 and 0.81 . The internal consistency of the factors was evaluated by item analysis and Cronbach's alpha. The alpha values were $0.87,0.84$ and 0.86 . Statistically, the validity and reliability of the instrument were good.

\subsection{Ethical Consideration}

Ethical permission was granted by the authorities of all participating hospitals, and the study was also approved by the Regional Ethical Review Boards. Each of the questionnaires for parents, nurses and physicians was accompanied by a covering letter which briefly described the study and its purpose, provided an affirmation of confidentiality and voluntary participation, and gave the researchers' contact information. The respondents were also able to leave the questionnaires in sealed envelopes that in themselves were clear evidence of voluntary par- 
ticipation and anonymity.

\subsection{Data Analysis}

The data were analyzed using PASW ${ }^{\circledR}$ Statistics 18 . Descriptive statistical analyses were undertaken to examine the demographic details, participants' preferred music and its expected effects on infants, parents and staff. The five dimensions in the Likert-scale statements were divided into three classes "agree" ("totally agree" to "agree to some extent"), "don't know", and "disagree" ("totally disagree" to "disagree to some extent").

The factor analysis, using principal component analysis with varimax rotation, produced a result of a total of three factors from the participants' expectations regarding the effects of preferred music. The sum variables were formed on the basis of factor analysis (factor loadings $>0.4$ ), and the internal consistency of these were tested using Cronbach's alpha test. Correlations between the groups of respondents (parents, nurses and doctors) and background details were conducted with the Chisquare test. Logistic regression analysis was undertaken to examine which background details explained the par- ticipants' expectations of using music in NICU. For that the dependent variables (sum variables) were reclassified into two responses: 1 = "totally agree"/"agree to some extent" $(1-2.49)$ and $0=$ "don't know"/"totally disagree"/“disagree to some extent" (2.5 - 5). P-values $\leq$ 0.05 were interpreted as statistically significant.

\section{RESULTS}

\subsection{Demographic Details}

Most of the participants were female (88\%) and their age ranged from 18 to 62 years, with a mean of 36.3 (SD = 9.9). About half of them had at least two children of their own. Forty-four percent of the participants were used to listening to music for one hour or more during their leisure time per day, and a few $(25 \%)$ of them had some musical training. Experiences of using music in NICU was not common among the participants, and slightly over half of them had experienced disturbing noises in the intensive care unit caused mainly by the alarm sounds of monitors or disruptive talking.

All the demographic details shown in Table 1 indicated

Table 1. Demographic details of the participants $(n=508)$.

\begin{tabular}{|c|c|c|c|c|}
\hline Demographics & Parents n $(\%)$ & Nurses n $(\%)$ & Physicians n (\%) & All n (\%) \\
\hline \multicolumn{5}{|l|}{ Gender } \\
\hline Male & $26(13)$ & $1(1)$ & $33(33)$ & $60(12)$ \\
\hline Female & $171(87)$ & 209 (99) & $68(67)$ & $448(88)$ \\
\hline \multicolumn{5}{|l|}{ Age (years) } \\
\hline 34 or less & $139(71)$ & $89(44)$ & $24(24)$ & $252(50)$ \\
\hline 35 or more & $58(29)$ & $115(56)$ & $77(76)$ & $250(50)$ \\
\hline \multicolumn{5}{|l|}{ Number of their own children } \\
\hline $0-1$ & $107(54)$ & $107(52)$ & $33(33)$ & $247(49)$ \\
\hline 2 or more & $90(46)$ & $100(48)$ & $67(67)$ & $257(51)$ \\
\hline \multicolumn{5}{|c|}{$\begin{array}{l}\text { Average length of time of listening to } \\
\text { music daily during leisure time }\end{array}$} \\
\hline$<1$ hour & $108(55)$ & $100(48)$ & $78(77)$ & $286(56)$ \\
\hline 1 hour or more & $89(45)$ & $109(52)$ & $23(23)$ & $221(44)$ \\
\hline \multicolumn{5}{|l|}{ Musical training } \\
\hline No & $160(82)$ & $163(78)$ & $58(57)$ & $381(75)$ \\
\hline Yes & $37(18)$ & $46(22)$ & $43(43)$ & $126(25)$ \\
\hline \multicolumn{5}{|c|}{ Experiences of using music in NICU } \\
\hline No/not sure & $176(89)$ & $116(56)$ & $89(88)$ & $381(75)$ \\
\hline Yes & $21(11)$ & $92(44)$ & $12(12)$ & $125(25)$ \\
\hline \multicolumn{5}{|c|}{ Experiences of disturbing noise in NICU } \\
\hline No/not sure & $159(81)$ & $28(13)$ & $37(37)$ & $224(44)$ \\
\hline Yes & $38(19)$ & $182(87)$ & $64(63)$ & $284(56)$ \\
\hline
\end{tabular}


that there were significant differences between the parents', nurses' and physicians' demographics $(\mathrm{p}<0.001)$.

\subsection{Participants’ Preferred Music}

Slightly over half of the participants $(64 \%)$ preferred recorded music for infants in the NICU. The most frequent choices were classical music, children's songs, and other sounds such as instrumental or sounds of nature soothing the infants. Pop/rock, hit, religious or folk songs were rarely preferred. Thirty six percent of the participants preferred live music; the most frequently reported type of live music was singing or humming by nurses or mothers (Table 2).

The groups of respondents were significantly related to the preferred music in NICU. The parents agreed live music to be the more suitable choice for infants, compared with the nurses' and physicians' musical preferences ( $p<0.001$, parents $49 \%$ vs. nurses $26 \%$ vs. physicians $30 \%)$.

\subsection{Effects of Preferred Music for Infants, Parents and Staff}

The participants strongly expected that music would have many positive effects on the infants in the NICU (Table 3). The majority agreed that the preferred music, recorded or live, could increase the feeling of security $(81 \%)$, decrease stress $(80 \%)$, improve sleep $(74 \%)$, reduce heart rate $(70 \%)$, and decrease crying $(67 \%)$ among infants. However, over half of the participants answered

Table 2. Participants' preferred music in NICU $(n=508)$.

\begin{tabular}{lcc}
\multicolumn{1}{c}{ Type of preferred music } & $\mathrm{n}$ & $\%$ \\
\hline Recorded music & 322 & 64 \\
Classical music & 175 & 54 \\
Children's songs & 81 & 25 \\
Other music/sounds ${ }^{*}$ & 37 & 11 \\
Pop/rock music & 15 & 5 \\
Hit songs & 7 & 2 \\
Religious song & 4 & 1 \\
Folk song & 1 & 1 \\
Don't know & 2 & 1 \\
Live music & 179 & 36 \\
Nurse's/mothers' singing or humming & 129 & 72 \\
Other music/sounds ${ }^{*}$ & 13 & 7 \\
Don't know & 37 & 21 \\
\hline
\end{tabular}

* Other music/sounds included instrumental or relaxation music, as well as different sounds of nature in order to sooth the infants. "don't know" about the effects of music on their infant's growth and weight gain, and the length of hospitalization.

Using music in NICU was also beneficial for the parents and staff (Table 3). Most of the participants agreed that music, in particular, could increase coziness and comfort in the ward (87\%), having a positive effect on the parents' mood $(81 \%)$, stress $(78 \%)$ and satisfaction with the care $(76 \%)$. In addition, music could also improve the staff's mood (71\%), increase their job satisfaction $(70 \%)$, and increase overall staff satisfaction (52\%).

The parents were in greater agreement that the music could benefit the infants compared with the nurses' and physicians' expectations of the effects of music $(\mathrm{p}<$ 0.001 , parents $71 \%$ vs. nurses $58 \%$ vs. physicians $43 \%$ ). The same tendency was observed concerning the effects of music on parents ( $p<0.001,81 \%$ vs. $77 \%$ vs. $66 \%$ ). Instead, it was the nurses who agreed most that the music could have positive effects on the staff in NICU (p < 0.001 , nurses $61 \%$ vs. parents $45 \%$ vs. physicians $42 \%$ ).

\subsection{Background Details Explaining the Effects of Preferred Music}

The background details including age, average length of time listening to music, musical training and experiences of using music in NICU as shown in Table 1 explained significantly the participants' expectations concerning the effects of their preferred music. Respondents who themselves listened to music a lot agreed more that their preferred music could also benefit the infants $(\mathrm{p}=0.035$, OR 1.20) and staff ( $p<0.001$, OR 1.47). It also appeared that respondents with musical training $(\mathrm{p}<0.001$, OR $2.11)$ and experiences of music in NICU $(p<0.001$, OR 2.41) agreed more that music could have positive effects on the infants, while younger participants were more convinced about the benefits of music to parents $(p=$ 0.002 , OR 0.96).

\section{DISCUSSION}

Our study yielded knowledge about using music in NICU from the viewpoints of parents, nurses and physicians, and looked for the possible differences between them. It appeared that slightly over half of the participants preferred recorded music for infants. However, it must be noted that the parents agreed that live music, including mostly singing or humming, was the more suitable choice for infants than nurses and physicians. The explanation for this result might be that health care providers are probably much more familiar with recorded music in the NICU environment, and this kind of music is assumed to be easily implemented in practice. Otherwise, parents might expect that live music is more beneficial because it can, for example, enhance interaction 
Table 3. Participants' expectations concerning the effects of preferred music on infants, parents and staff in NICU (n=508).

\begin{tabular}{|c|c|c|c|c|c|}
\hline Expectations concerning the effects of preferred music & Agree $\mathrm{f}(\%)$ & $\begin{array}{c}\text { Don't know } \\
\mathrm{f}(\%)\end{array}$ & $\begin{array}{c}\text { Disagree } \\
\mathrm{f}(\%)\end{array}$ & $\begin{array}{c}\text { Number of } \\
\text { items }\end{array}$ & $\alpha$ \\
\hline Infants & $303(60)$ & $196(38)$ & $9(2)$ & 9 & 0.87 \\
\hline Increases the feeling of security in infants & $410(81)$ & $83(16)$ & $13(3)$ & & \\
\hline Decreases the stress experience of infants & $405(80)$ & $92(18)$ & $10(2)$ & & \\
\hline Improvement in infants' sleep & $373(74)$ & $117(23)$ & $17(3)$ & & \\
\hline Reassures the heart rate & $352(70)$ & $139(27)$ & $16(3)$ & & \\
\hline Decreases the infants' crying & $336(67)$ & $138(27)$ & $32(6)$ & & \\
\hline Relieves the infants' pain & $260(51)$ & $203(40)$ & $44(9)$ & & \\
\hline Influences reduction of blood pressure & $248(49)$ & $243(48)$ & $16(3)$ & & \\
\hline Enhances the infants' growth and weight gain & $187(37)$ & $261(52)$ & $57(11)$ & & \\
\hline Reduces the length of hospitalization & $74(15)$ & $315(62)$ & $118(23)$ & & \\
\hline Parents & $385(76)$ & $113(22)$ & $9(2)$ & 7 & 0.84 \\
\hline Increases coziness and comfort in the ward & $440(87)$ & $55(11)$ & $11(2)$ & & \\
\hline Has a positive effect on the caregiver's mood & $412(81)$ & $82(16)$ & $13(3)$ & & \\
\hline Decreases the parent's stress & $394(78)$ & $88(17)$ & $25(5)$ & & \\
\hline Increases satisfaction with the care their infant receives & $383(76)$ & $107(21)$ & $17(3)$ & & \\
\hline Alleviates anxiety & $360(71)$ & $111(22)$ & $36(7)$ & & \\
\hline Influences the parents' desire to continue music at home & $361(71)$ & $123(24)$ & $23(5)$ & & \\
\hline Helps a mother/father get acquainted with their baby & $229(45)$ & $210(42)$ & $68(13)$ & & \\
\hline Staff & $258(51)$ & $218(43)$ & $30(6)$ & 5 & 0.86 \\
\hline Improves the staff's mood & $359(71)$ & $126(25)$ & $21(4)$ & & \\
\hline Increases staff's enjoyment in their job & $353(70)$ & $126(25)$ & $26(5)$ & & \\
\hline Increases staff's satisfaction & $263(52)$ & $222(44)$ & $21(4)$ & & \\
\hline Helps to concentrate and outperform the tasks & $175(35)$ & $217(43)$ & $114(22)$ & & \\
\hline Enables staff to feel proud of their job & $138(27)$ & 249 (49) & $119(24)$ & & \\
\hline
\end{tabular}

between the infants and their caregivers, and is a more natural way to communicate with the infants. In the study of Arnon [11] parents considered live music therapy significantly more effective than the other therapies. The results also showed that both medical personnel and parents preferred live music therapy to recorded music and no music therapies, which in part conflicts with the results of our study. According to Standley [6] live singing is recommended when it is steady, quiet, soothing and infant directed. It also enables the infants to hear parent voices live at the bedside [8], a factor which is important to the infant's development.

When using recorded music it should also be soothing for the infants, in which case lullabies and classical music are the most suitable alternatives $[6,15]$. In our study, the participants reported choosing mostly classical music or children's songs, while pop/rock, hit, religious or folk songs were rarely preferred. This probably indicates that the participants choose the type of music for the needs of infants and not based on their own entertainment in NICU.

However, the participants expected that the music they preferred would have significantly positive effects not only on the infants but also on the parents and staff. The majority agreed that music could have many beneficial effects for the infants, such as increasing the feeling of security and the decrease of stress, but would also improve the parents' and staff's mood and thereby increase the overall feeling of comfort in the ward. The results are congruent with the study of Kemper et al. [25] about the positive effects of music. The authors examined attitudes and expectations regarding music therapy for premature 
infants among nurses and physicians in NICU. According to the results, the staff expected that music could especially reduce infants' stress and crying, but also decrease parental stress and help them to focus and enhance their performance of required tasks. In addition, several randomized studies have been conducted that demonstrate that music has positive consequences both on the short-term and long-term outcomes in infants $[5,11,14$, 17], but there is a lack of studies dealing with the outcomes among caregivers [11,22].

There were differences between the groups of respondents concerning the expectations about the effects of music in NICU. The parents agreed most that their preferred music could benefit the infants and themselves as parents, while nurses agreed most that the music could have positive effects on the staff. It is understandable that it is easier for the participants to assess the effects of music on themselves than on others, because the choice of music has an individual meaning to everyone, something which also influences the expectations regarding the benefits of music. When looking at the demographic details of the participants, it was interesting to note that only a few parents had experiences of disturbing noise in NICU when compared to experiences among the health care providers. The explanation for this result might be that the latter are for the most part nurses who spend much of their time in caring for the infants and are continually exposed to the noises caused by the alarm sounds of the monitors on a daily basis.

The results of our study indicated that some of the background details explained the participants' expectations concerning the effects of their preferred music. Respondents who themselves listened to music a lot, or had some musical training or experiences of music in NICU, were in greater agreement that music could have positive effects on the infants or parents. The results are partly congruent with the survey study of staff [25] in which the respondents who reported some musical training were more likely to desire music in NICU than those without such training. It seems that the participants' personal experiences of music will influence their expectations of the beneficial effects of music more than the general demographics, but more study is needed about this topic in the future.

\section{LIMITATIONS}

Although a valid and reliable survey instrument was used to collect the data from the viewpoints of parents, nurses and physicians, the results may appear to be more positive than they really were in practice, because the participants who were against using music in NICU might have refused to fill in the questionnaire. In addition, it must be emphasized that this study approves results only about the expectations concerning the possible effects of music among caregivers. In reality, there are several factors that should be considered when making the decision to use music in hospital. First of all, the use of music should be based on the infant's current needs of appropriate stimulation, but, unfortunately, these characteristics could not be taken into account in this questionnaire. However, we assume that our study gives an overall picture about the topic on the caregivers' expectations of using music in NICU and allows the generalization of the results in Finnish neonatal intensive care units.

\section{CONCLUSION}

The participants preferred recorded music for infants in NICU. However, the parents agreed live music to be the more suitable choice for their babies than nurses and physicians. This disagreement is important to consider in practice when making the decision as to whether to use music in NICU. Overall, the participants strongly expected that their preferred music could be beneficial both for the infants, parents and staff. This result may positively influence the introduction of music in the future because only a few respondents actually reported having experiences of using music in their units during the period of data collection. The personal experiences of music seemed to possess the expectations concerning the possible effects of music in NICU.

\section{ACKNOWLEDGEMENTS}

We would like to thank the Finnish Cultural Foundation for providing funding for this research.

\section{REFERENCES}

[1] Anand, K.J.S., Aranda, J.V., Berde, C.B., et al. (2006) Summary Proceedings from the Neonatal Pain-Control Group.

http://www.pediatrics.org/cgi/doi/10.1542/peds.2005-062 $\underline{0 \mathrm{C}}$

[2] Barreto, E.D., Morris, B.H., Philbin, M.K., Gray, L.C. and Lasky, R.E. (2006) Do former preterm infants remember and respond to neonatal intensive care unit noise? Early Human Development, 82, 703-707. doi:10.1016/j.earlhumdev.2006.02.009

[3] Wachman, E.M. and Lahav, A. (2011) The effects of noise on preterm infants in the NICU. Archives of Disease in Childhood-Fetal and Neonatal Edition, 96, F305-F309. doi:10.1136/adc.2009.182014

[4] Hartling, L., Shaik, M.S., Tjosvold, L., Leicht, R., Liang, Y. and Kumar, M. (2009) Music for medical indications in the neonatal period: A systematic review of randomized controlled trials. Archives of Disease in ChildhoodFetal and Neonatal Edition, 94, F349-F354. doi:10.1136/adc.2008.148411 
[5] Olischar, M., Shoemark, H., Holton, T., Weninger, M. and Hunt, R.W. (2011) The influence of music on aEEG activity in neurologically healthy newborns $\geq 32$ weeks' gestational age. Acta Paediatrica, 100, 670-675. doi:10.1111/j.1651-2227.2011.02171.x

[6] Standley, J.M. (2002) A meta-analysis of the efficacy of music therapy for premature infants. Journal of Pediatric Nursing, 17, 107-113. doi:10.1053/jpdn.2002.124128

[7] Kellam, B. and Bhatia, J. (2008) Sound spectral analysis in the intensive care nursery: Measuring high-frequency sound. Journal of Pediatric Nursing, 23, 317-323. doi:10.1016/j.pedn.2007.09.009

[8] Graven, S.N. (2000) Sound and the developing infant in the NICU: Conclusions and recommendations for care. Journal of Perinatology, 20, S88-S93. doi:10.1038/sj.jp.7200444

[9] Philbin, M.K., Robertson, A. and Hall, J.W. (2008) Recommended permissible noise criteria for occupied, newly constructed or renovated hospital nurseries. Advances in Neonatal Care, 8, S11-S15. doi:10.1097/01.ANC.0000337267.47599.80

[10] American Academy of Pediatrics, Committee on Environmental Health (1997) Noise: A hazard for the fetus and newborn. Pediatrics, 100, 724-727. doi:10.1542/peds.100.4.724

[11] Arnon, S., Shapsa, A., Forman, L., Regev, R., Bauer, S., Litmanovitz, I. and Dolfin, T. (2006) Live music is beneficial to preterm infants in the neonatal intensive care unit environment. Birth, 33, 131-136. doi:10.1111/j.0730-7659.2006.00090.x

[12] Butt, M.L. and Kisilevsky, B.S. (2000) Music modulates behavior of premature infants following heel lance. The Canadian Journal of Nursing Research, 31, 17-39.

[13] Chou, L.-L., Wang, R.-H., Chen, S.-J. and Pai, L. (2003) Effects of music therapy on oxygen saturation in premature infants receiving endotracheal suctioning. The Journal of Nursing Research, 11, 209-215. doi:10.1097/01.JNR.0000347637.02971.ec

[14] Caine, J. (1991) The effects of music on the selected stress behaviors, weight, caloric and formula intake, and length of hospital stay of premature and low birth weight neonates in a newborn intensive care unit. Journal of $\mathrm{Mu}$ sic Therapy, 28, 180-192.

[15] Lubetzky, R., Mimounti, F.B., Dollberg, S., Reifen, R., Ashbel, G. and Mandel, D. (2010) Effect of music by
Mozart on energy expenditure in growing preterm infants. Pediatrics, 125, e24-e28. doi:10.1542/peds.2009-0990

[16] Standley, J.M. (2003) The effect of music-reinforced nonnutritive sucking on feeding rate of premature infants. Journal of Pediatric Nursing, 18, 169-173. doi:10.1053/jpdn.2003.34

[17] Whipple, J. (2008) The effect of music-reinforced nonnutritive sucking on the state of preterm, low birth weight infants experiencing heelstick. Journal of Music Therapy, 45, 227-272.

[18] Yildiz, A. and Arikan, D. (2012) The effects of giving pacifiers to premature infants and making them listen to lullabies on their transition period for total oral feeding and sucking success. Journal of Clinical Nursing, 21, 644-656. doi:10.1111/j.1365-2702.2010.03634.x

[19] Whipple, J. (2000) The effect of parent training in music and multimodal stimulation on parent-neonate interaction in the neonatal intensive care unit. Journal of Music Therapy, 37, 250-268.

[20] Schlez, A., Litmanovitz, I., Bauer, S., Dolfin, T., Regev, R. and Arnon, S. (2011) Combining kangaroo care and live harp music therapy in the neonatal intensive care unit setting. The Israel Medical Association Journal, 13, 354 358.

[21] Lai, H.-L., Chen, C.-J., Peng, T.-C., Chang, F.-M., Hsieh, M.-L., Huang, H.-Y. and Chang, S.-C. (2006) Randomized controlled trial of music during kangaroo care on maternal state anxiety and preterm infants' responses. International Journal of Nursing Studies, 43, 139-146. doi:10.1016/j.ijnurstu.2005.04.008

[22] Kemper, K.J. and Danhauer, S.C. (2005) Music as therapy. Southern Medical Journal, 98, 282-288. doi:10.1097/01.SMJ.0000154773.11986.39

[23] Franck, L., Cox, S., Allen, A. and Winter, I. (2004) Parental concern and distress about infant pain. Archives of Disease in Childhood-Fetal and Neonatal Edition, 89, F71-F75. doi:10.1136/fn.89.1.F71

[24] Lai, H.L. and Good, M. (2002) An overview of music therapy. The Journal of Nursing, 49, 80-84.

[25] Kemper, K.J., Martin, K., Block, S.M., Shoaf, R. and Woods, C. (2004) Attitudes and expectations about music therapy for premature infants among staff in a neonatal intensive care unit. Alternative Therapies in Health and Medicine, 10, 50-54. 